\title{
Axon Guidance in Muscleless Chick Wings: The Role of Muscle Cells in Motoneuronal Pathway Selection and Muscle Nerve Formation
}

\author{
Kevin A. Phelan and Margaret Hollyday ${ }^{a}$ \\ Committee on Neurobiology, The University of Chicago, Chicago, Illinois 60637
}

\begin{abstract}
The role of myogenic cells in accurate pathway selection and muscle nerve formation was studied in chick embryos. Myotubes were eliminated from the forelimb of the chick embryo by extirpating the somites, which give rise to myogenic cells. Other elements of the wing tissue, connective tissue, and cartilagenous elements derived from the somatopleure, were left intact. Injections of WGA-HRP were made into either dorsal or ventral nerve trunks in the wing and the positions of retrogradely labeled motoneurons determined. The positions of the motoneurons within the brachial lateral motor column were appropriate for the injection made. Thus, the accuracy of the motoneuronal projections was unaffected by the absence of muscle cells.

The absence of myotubes was not correlated with the absence of muscle nerves. Muscle nerves were consistently observed in muscleless wings until stage 36 , the oldest stage examined. Muscle nerves in muscleless wings differed from those in normal wings in that they were smooth and stubby, and lacked the normal pattern of intramuscular nerve branches. From these studies we conclude that muscle cells are not necessary for accurate motor axon guidance into the periphery along the routes of major nerve trunks, nor for the formation of muscle nerves. By inference, somatopleural derivatives provide sufficient cues for selection of specific axonal pathways and for patterning of muscle nerves within the chick limb.
\end{abstract}

The formation of specific neuronal connection patterns and the role of target cells in this process is a central problem in developmental neurobiology. A report by Lewis et al. (1981) concluded that major nerve trunks formed in the absence of muscle, but that fibers which normally diverge from these trunks to form muscle nerves did not do so. Their techniques allowed them to examine only the gross neuronal projection pattern of axons within the limb, without providing any information on the origin of the fibers (e.g., whether these axons were sensory or motor) or the specificity of the pattern of innervation (e.g., if

\footnotetext{
Received Dec. 18, 1989; revised Mar. 15, 1990; accepted Mar. 22, 1990.

We would like to thank Nicole LeDouarin and Radovan Zak for generously providing monoclonal antibodies, and M. J. Ferns, C. Gutman, E. Markakis, and M. L. Perez for comments on the manuscript. This work was supported by NIH Predoctoral Fellowship GM-07839 to K.A.P. and NIH NS-25340 to M.H.

Correspondence should be addressed to Kevin A. Phelan at his present address: Department of Pathology and Center for Neurobiology and Behavior, College of Physicians and Surgeons, Columbia University, 630 West 168th Street, New York, NY 10032 .

${ }^{2}$ Present address: Department of Biology, Bryn Mawr College, Bryn Mawr, PA 19010.

Copyright $@ 1990$ Society for Neuroscience $0270-6474 / 90 / 082699-18 \$ 03.00 / 0$
}

they were motor, whether they projected correctly). Thus, it is not known whether motor axons can select the proper initial pathway in the absence of their target cell type. The experiments described here were designed to test this question through a combination of experimental embryological manipulations and axonal pathway tracing.

Chick-quail chimera studies by others have shown that the limb tissue is of dual embryonic origin (Chevallier et al., 1977; Christ et al., 1977). Appendicular muscle cells, whose precursors migrate laterally into the limb bud from their original location adjacent to the neural tube, are derived exclusively from somites. Cartilagenous and connective tissue elements are derived from the somatic mesoderm of the somatopleure, also called the lateral plate. Since muscle precursor cells migrate $1 \mathrm{~d}$ in advance of the earliest motor axon outgrowth, it is possible that myogenic cells affect the initial inncrvation of limb tissuc. We have examined this possibility by surgically removing the somites before the onset of this migration and mapping the projections of motor axons into these muscleless limbs.

We have taken advantage of the dual embryonic origin of limb tissue in order to produce chicken wings which are totally devoid of muscle. By surgically removing structures containing the muscle precursor cells, the somites, prior to their lateral migration, muscle can be subtracted from the forelimb early in development. This allows the later motor axons to grow out in the absence of their normal targets.

Somatic motoneurons are topographically distributed within the brachial lateral motor column $(1 \mathrm{mc})$. Motoneurons which innervate muscles derived from the dorsal muscle mass are located in the ventrolateral aspect of the $1 \mathrm{mc}$, while those neurons which innervate muscles derived from the ventral muscle mass lic further dorsomedially within the lmc (Ohmori ct al., 1982; Straznicky and Tay, 1983; M. Hollyday and R. Jacobson, unpublished observations). Along the rostrocaudal axis, motoneurons which innervate proximal shoulder musculature tend to lie in more rostral segments of the lmc than those neurons which innervate distal muscles of arm and forearm. These rules of motoneuron location enable us to assess whether these cells project axons to appropriate nerves within the wing in the absence of muscle.

Forelimb motor axons exit from the ventral portion of the spinal cord, run in the spinal nerves 13-17, and converge at the base of the wing bud to contribute to the formation of the brachial plexus. At the plexus region, axons diverge to form 2 major nerve trunks: $n$. brachialis superior, which projects to muscles derived from the dorsal muscle mass, and $\mathrm{n}$. brachialis inferior, which projects to muscles derived from the ventral 


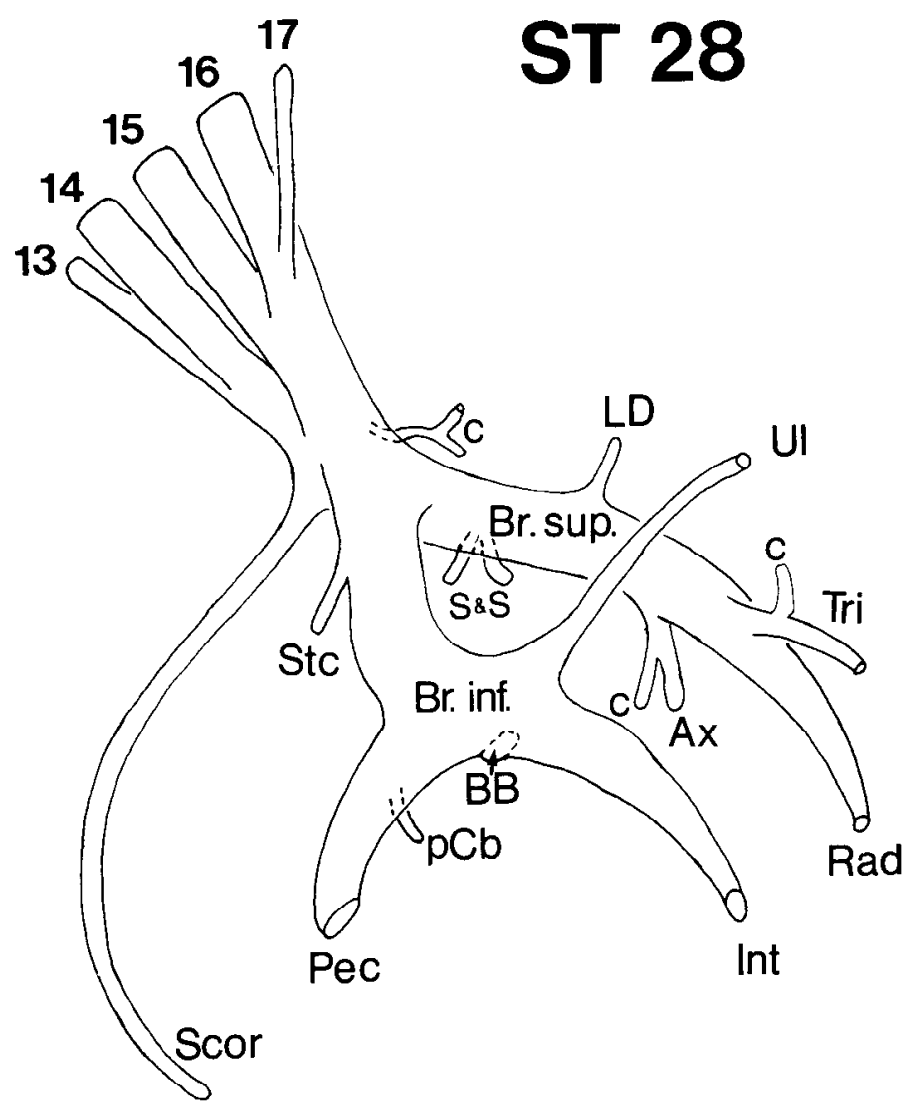

Figure 1. Reconstruction of the neuronal projection pattern to the proximal chick wing at stage 28 [modified from Hollyday (1983)]. The numbers 13-17 refer to the spinal segments containing the brachial lateral motor column. Abbreviations: $A X$, axillaris; $B B$, biceps brachii; $B r$. inf., brachialis inferior; $B r$. sup., brachialis superior; $C$, cutaneous branch; $p C b$, coracobrachialis posterior; Int, interosseous; $L D$, latissimus dorsi; Pec. pectoralis; Rad, radialis; $S \& S$, subscapularis and subcoracoideus; Scor, supracoracoideus; Stc, sternocoracoideus; Tri, triceps brachii; $U l$, ulnaris. The following innervate ventrally derived muscles: Br. inf., Pec, Scor, pCb [Sullivan (1962) classifies this as a dorsally derived muscle], Stc, BB, Int, Ul; the following innervate dorsally derived muscles: Br. sup., Ax, LD, S\&S, Tri, Rad.

muscle mass (Fig. 1). These 2 major nerve trunks are separated by the humeral precursor, with $\mathrm{n}$. brachialis superior lying dorsal to it and $\mathrm{n}$. brachialis inferior lying ventrally. The spatial separation of the 2 major nerve trunks in the wing makes it possible to inject selectively either $\mathrm{n}$. brachialis superior or $\mathrm{n}$. brachialis inferior with the pathway-tracer HRP and to examine after retrograde axonal transport where the cell bodies of the injected motor axons lie within the spinal cord. Whether the motoneurons projecting axons to the injection site have made appropriate or erroneous choices en route can be inferred from the position of their labeled cell bodies within the spinal cord and comparison to brachial motoneuronal maps from normal embryos.

In addition to examining the specificity of the motor projection within the major nerve trunks, ns. brachialis superior and inferior, we have also searched for the formation of muscle nerves throughout the paravertebral, shoulder, and humeral regions in the absence of muscle at stages prior to motoneuronal cell death. In contrast to a previous report (Lewis et al., 1981), we found that muscle nerve formation was not hindered by the absence of muscle.
Portions of this work have been previously published in abstract form (Phelan and Hollyday, 1986).

\section{Materials and Methods}

White Leghorn chicken eggs (Shaw's IIatchery, Oxford, PA) were incubated in a forced-draft incubator at $38.5^{\circ} \mathrm{C}$ for approximately $48 \mathrm{hr}$ until they reached stage $11^{+}$to $13^{-}$(Hamburger and Hamilton, 1951). Embryos at these stages have 15-18 pairs of somites. In the wing region, the somitic mesoderm has not yet completely segmented to form somites, and no muscle precursor cells have migrated into the wing bud. Muscle precursor cells for the wing muscles delaminate from brachial somites beginning at stage 14 (Christ et al., 1977).

Birthdating studies have shown that forelimb somatic motoneuron generation is not initiated until stage 15 (Hollyday and Hamburger, 1977). The somite extirpations were done in these animals between stages $11^{+}$and $13^{-}$. Thus, these motoneurons are never exposed to myogenic precursors at anytime during generation or axonogenesis.

In preparation for somite removal, a window was opened in the shell, and the eggshell membranes were removed. The embryo was raised up through this window by dripping approximately $2 \mathrm{ml}$ of sterile chick Ringers into the egg. Then approximately $100 \mu \mathrm{l}$ of filtered blue/black ink (Parker \#30070) was injected into the yolk sac beneath the blastoderm to visualize the embryo for surgery. Using electolytically sharpened tungsten needles, the vitelline membrane was torn away to expose the embryo. Only the right side was operated upon in each embryo, leaving the left side intact as a control. The ectoderm was slit adjacent to the neural tube and was carefully peeled back to expose the underlying somitic mesoderm; caution was taken so that no somitic cells adhered to the ectoderm.

The number of somites was determined using the counting methods of Beresford (1983). Those somites and the portions of the undivided segmental plate which would give rise to the wing musculature were then removed with tungsten needles. Studies by others have shown that the muscle cells in the chick wing are normally derived from somites 16-21 inclusive (Christ et al., 1977; Beresford, 1983). In addition, somitic mesoderm from adjacent rostral and caudal segments was also removed to eliminate muscle precursor cell migration into the limb from adjacent segments. Thus, a typical operation extirpated somite 12 through presumptive somite 24

Somite removal was accomplished by gently teasing the somites, which are anchored by collagen fibrils, away from the adjacent neural tube the underlying endoderm and the lateral plate mesoderm; great care was taken not to disrupt the dorsal aorta or posterior cardinal vein in the surgical region (Fig. 2). The excised somitic mesoderm was removed from the egg, thus eliminating any humoral influences that it might have on the developing nervous system. Next the embryo was lowered back into the shell by withdrawing $1-1.5 \mathrm{ml}$ of albumin/saline from the egg. Finally, the egg was resealed with a glass coverslip and paraffin and returned to the incubator.

When embryos reached stages $28-30$ ( $6.5 \mathrm{~d}$ of incubation), they were removed from the egg for study of both axonal projections and muscular depletion. These stages were chosen for 3 reasons: axons have projected in to the wing and have segregated into the characteristic peripheral nerve pattern proximally (Hollyday, 1983; Fig. 1); the period of naturally occurring motoneuronal cell death in the brachial spinal cord has not yet begun (Oppenheim and Majors-Willard, 1978; Laing, 1982; K. Phelan and M. Hollyday, unpublished observations); and the antigens of the muscle-specific immunological markers described below are normally expressed in all primary myotubes and in sufficient quantity to be detected if present.

Muscle-specific immunological markers were used on lissue sections as probes for the presence of muscle precursor cells within the myotomal, dorsal, and ventral muscle mass regions. The first probe utilized was monoclonal antibody CCM $31 \mathrm{~A}$ (provided by Dr. R. Zak). CCM $31 \mathrm{~A}$ was generated against $12 \mathrm{~d}$ embryonic chick cardiac myosin and recognizes myosin heavy chain (Sweeney et al., 1984, 1989). A second marker used was monoclonal antibody 13F4 (provided by Prof. N. LeDouarin). 13F4 was made against $14 \mathrm{~d}$ chick Remak ganglion and recognizes an unidentified $54 \mathrm{kDa}$ protein within the myofibrillar Z-line, which is distinct from desmin (Rong et al., 1987). Experimental wings showing no immunoreactivity for either of the muscle-specific antibodies were classified as muscleless. In each embryo, strong immunoreactivity was detected for the muscle-specific marker on the contralateral unoperated side (Fig. 3). 


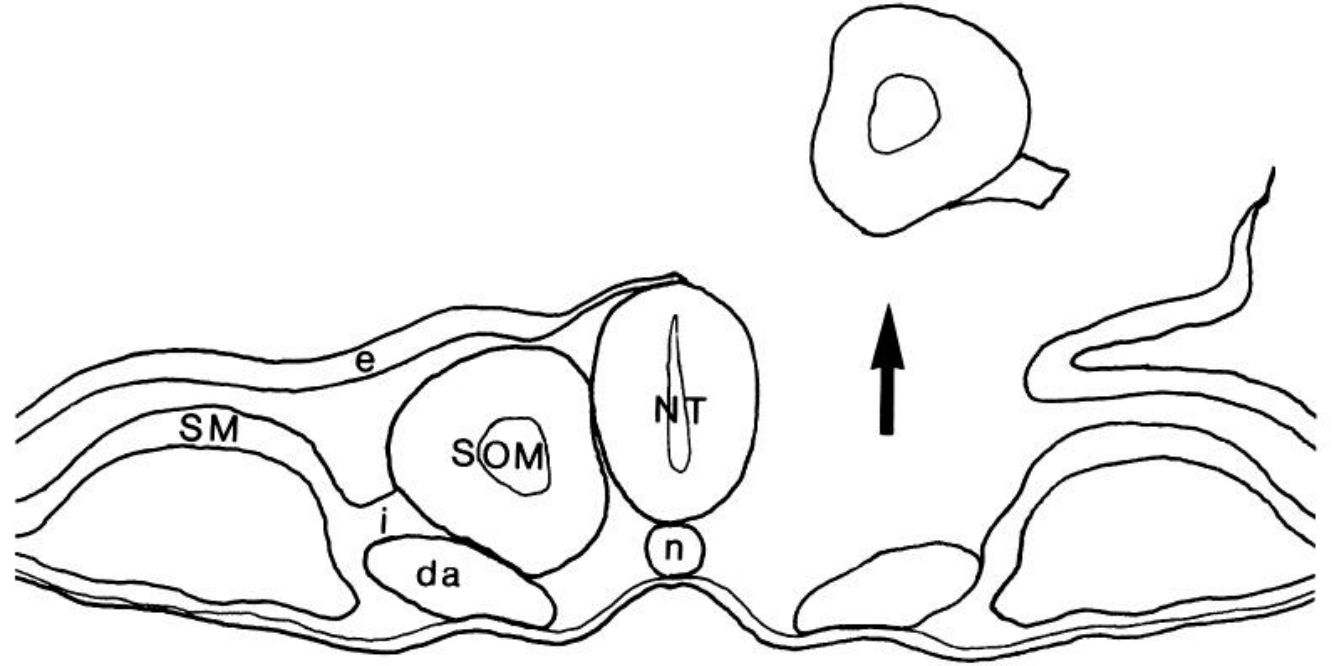

A

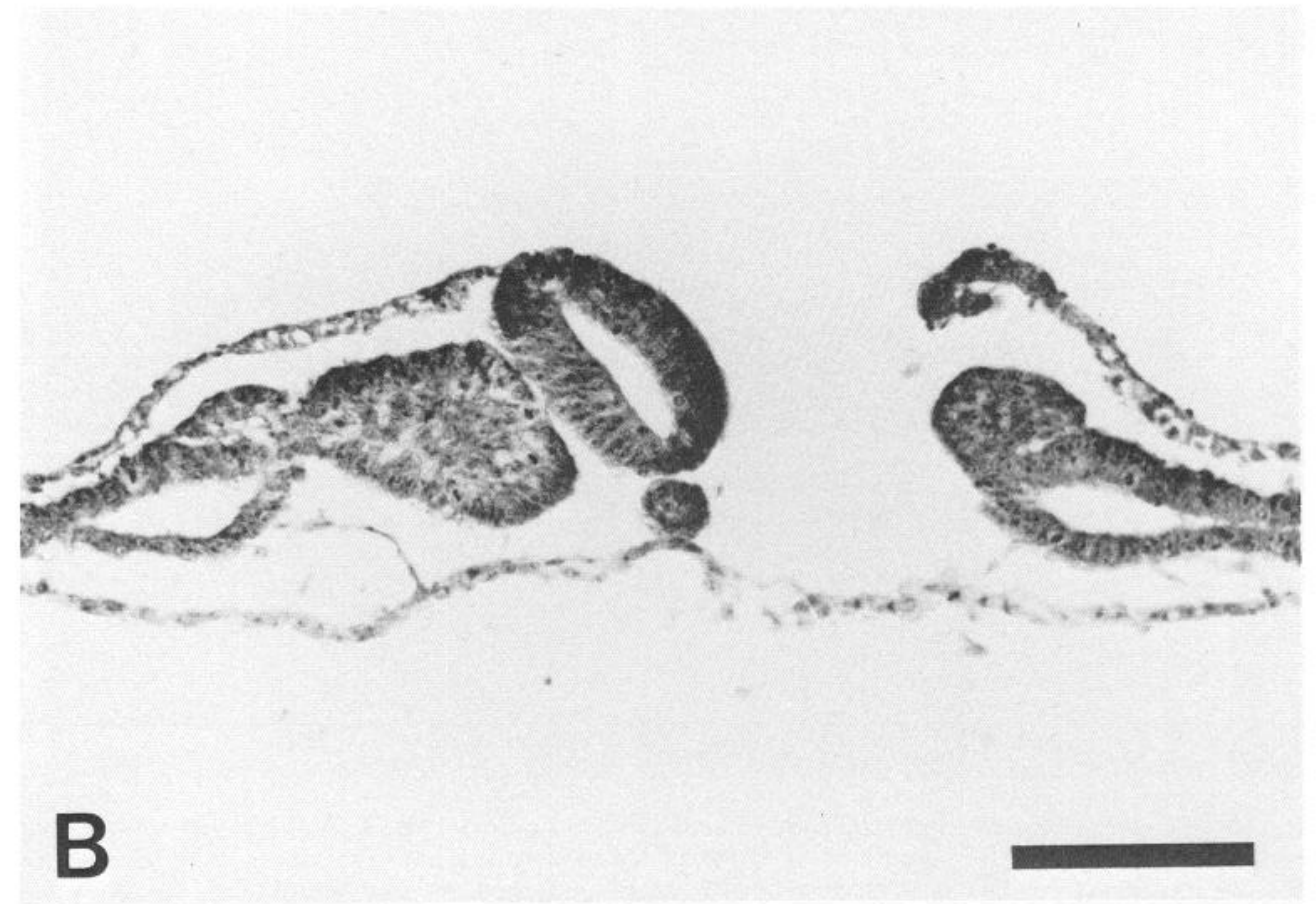

Figure 2. Unilateral surgical removal of somites. $A$, Line drawing at the level of the 13th somite in a stage 12 embryo schematically illustrating the surgical procedure performed. da, dorsal aorta; $e$, ectoderm; $i$, intermediate mesoderm; $N T$, neural tube; $n$, notochord; $S M$, somatic mesoderm; $S O M$, somite. $B$, Photomicrograph of transverse section at the same level in a similarly aged embryo fixed immediately after surgery. The total elimination of somitic mesoderm from one side is readily apparent; somatic mesoderm and neural tube remain intact. Hematoxylin and eosin stain. Scale bar, $100 \mu \mathrm{m}$.
In order to study the innervation pattern of experimental wings, we injected a mixture of HRP (Sigma, Type VI) and WGA-HRP dissolved in Tyrode's solution into 1 of 2 identified peripheral nerve trunks in the wing (Fig. 1). The injections were done after removing the embryo from the egg and placing it in a dish of oxygenated Tyrode's solution. The embryo was eviscerated, but a ventral laminectomy was not performed due to the fragility of the emerging motor axons on the experimental side. In the absence of somites, the axons emerging from the spinal cord were not tightly bundled into spinal nerves, but rather formed a diffuse sheet of axon fascicles extending from the spinal cord to the wing bud. Laminectomies on experimental embryos often resulted in the tearing of these axons and thus the failure of motoneuron cell bodies to label after peripheral injection. In each experimental embryo, HRP was injected into either $\mathrm{n}$. brachialis superior, distal to where axillaris and latissimus dorsi diverged from the nerve trunk, or into $\mathrm{n}$. brachialis inferior, distal to where pectoralis diverged from the ventral nerve trunk. The tracer material was taken up by axons and transported retrogradely to motoneuron cell bodies in the spinal cord, where it was visualized using appropriate histochemical techniques. The tracer was also transported anterogradely by injected nerve fibers allowing visualization of distal features of the nerve pattern such as muscle nerves and growth cones.

After the enzyme was injected, the embryo was put into fresh, oxygenated Tyrode's solution, and the dish was placed within a humidified, aerated chamber for $5 \mathrm{hr}$. This time period was sufficient to allow retrograde transport to motoneuron cell bodies within the spinal cord 

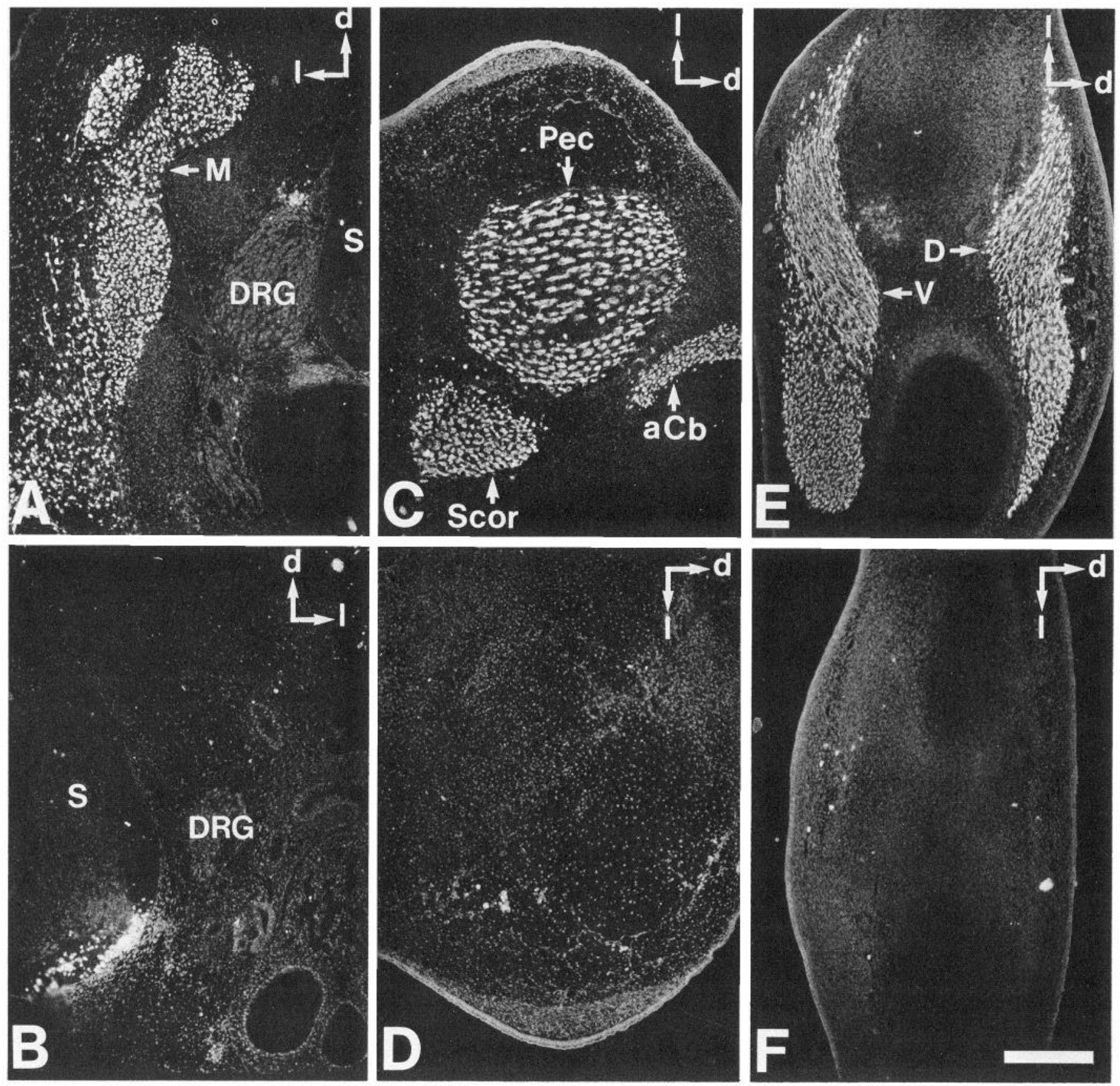

Figure 3. Comparison of $13 \mathrm{~F} 4$ immunoreactivity in stage 30 embryos having one normal and one muscleless wing. $A, C$, and $E$, Unoperated side of embryo; $B, D$, and $F$, side of embryo from which somites had been removed. $A$ and $B$. Axial regions adjacent to the spinal cord $(S)$ showing presence of 13F4-positive myotome $(M)$ in $A$ and its absence on the contralateral side in $B$. Intensely fluorescent cells ventral to the spinal cord in $B$ are blood cells. $C$ and $D$, Transverse sections through region of the muscles pectoralis $(P e c)$, supracoracoideus (Scor), and coracobrachialis anterior $(a C b) . E$ and $F$, Transverse sections through equivalent levels of the distal wing where dorsal and ventral muscle mass derivatives $(D$ and $V)$ normally form. Note lack of $13 \mathrm{~F} 4$ staining in $B, D$, and $F$, indicating the absence of muscle fibers in the experimental limb. Orientation axes in the upper right-hand corner of each panel indicate dorsal $(d)$ and lateral $(l)$ directions. $D R G$, dorsal root ganglion. Scale bar, $200 \mu \mathrm{m}$. Identical results were obtained using monoclonal antibody CCM 31A (Sweeney et al., 1984, 1989, data not shown).

and anterograde transport into axons within the distal forelimb. At the end of the transport period, embryos were fixed in either $4 \%$ paraformaldehyde or Bouin's fluid as described below.

The tissue was processed for HRP-reaction product and to detect the presence or absence of muscle proteins using 2 different sets of methods. The data from these 2 sets of experimental embryos were pooled since there were no differences between the results. The initial studies were done on embryos which had been fixed in $4 \%$ paraformaldehyde, sectioned on a cryostat at $40 \mu \mathrm{m}$, and then processed for HRP reaction product with cobalt-intensified DAB (Adams, 1981) and counterstained with cresyl violet. Alternate $10 \mu \mathrm{m}$ sections were collected for immunohistochemistry; the antibody used to probe for muscle fibers was CCM 31A (Sweeney et al., 1984, 1989). The primary antibody, an IgG, was visualized using a rhodamine-conjugated rabbit anti-mouse secondary antibody (Miles Scientific). Later in the study, embryos were fixed in Bouins, embedded in paraffin, and sectioned at $8 \mu \mathrm{m}$. This method produced better tissue preservation than was obtained in cryostat sections. The serial sections were mounted on glass slides and reacted in 

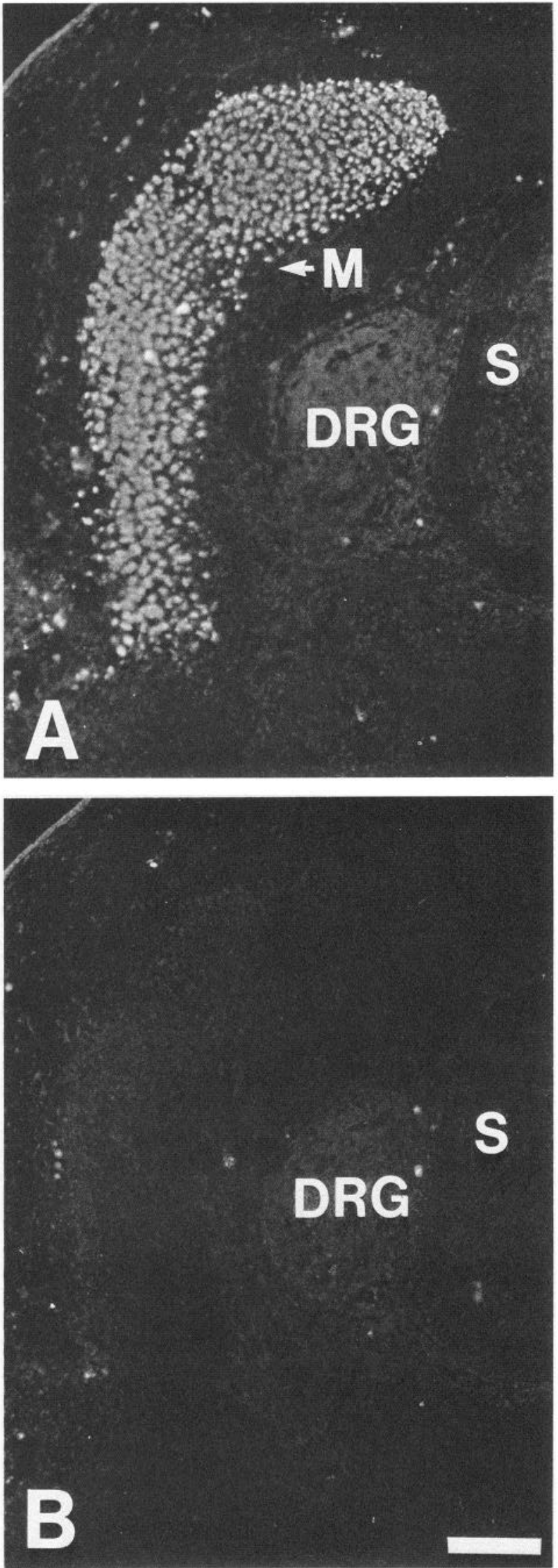

Figure 4. Experimental control demonstrating background fluorescence in the absence of primary antibody $13 \mathrm{~F} 4$. Transverse sections at the following way. The first 9 sections out of each group of 10 sections were mounted, reacted to detect the presence of HRP with peroxidaseantiperoxidase (PAP; Sternberger, 1979), and counterstained with hematoxylin and eosin. The remaining 10th sections were mounted on a different slide and probed for muscle precursor cells using mab 13F4 (Rong et al., 1987); indirect immunofluorescence was again used to detect the primary antibody. A fluorescein-conjugated rabbit anti-mouse IgM (ICN Immunobiologicals) was used to label the primary antibody. Sections used to control for the specificity of primary antibody binding were taken from the thoracolumbar region of the embryo, caudal to the experimental brachial level. These sections were processed in parallel except that the primary antibody was omitted from the protocol. In these control sections, only diffuse background fluorescence was observed (Fig. 4).

The slides processed for HRP reaction product were examined with a bright-field microscope. The rostrocaudal extent of the brachial lateral motor column was determined, and spinal cord segments were identified using ventral roots as landmarks. Within each section, the mediolateral position of each of the HRP-labeled motoneurons was determined and recorded, using hatchling motor pool maps (Ohmori et al., 1982; Straznicky and Tay, 1983; M. Hollyday and R. Jacobson, unpublished observations) as guides. These maps were also used to assess the appropriateness of labeled cells along the rostrocaudal length of the lateral motor column. The number of labeled dorsal root ganglion (DRG) cells was also recorded. The wings were examined to verify the specificity of the peripheral injection and to determine the peripheral nerve pattern.

The slides processed for immunoreactivity were examined on a Nikon Optiphot microscope equipped with epifluorescence. Each section was examined for the presence of muscle fibers. The routine screening of the sections was done with a $10 \times$ objective. In regions where there was some uncertainty about the presence or absence of immunoreactivity, the sections were examined at $40 \times$. Selected pairs of sections were photographed to compare similar levels in the operated and unoperated wings of the same embryo. Identical exposure and photographic printing conditions were used for each pair of photographs.

\section{Results}

\section{Production of embryos with muscleless wings}

The success of the operation to produce muscleless limbs was evaluated using 2 primary criteria. First, embryos having muscleless wings failed to move the experimental wing in ovo during a 5 min observation period. Operated wings containing muscle fibers typically displayed 1 or more movements during spontaneous activity periods (Hamburger and Balaban, 1963) which occurred during the period of observation. Out of 49 experimental embryos whose motility was observed, a total of 24 failed to show wing movements. Of these, 13 were later found to have some muscle fibers in the experimental wing. In no case were apparent wing movements observed in ovo in embryos which were later found to lack muscle histologically. The absence of motility was therefore a good, but not perfect, indicator of the absence of muscle.

The criterion given the greatest weight was the presence or absence of muscle-specific antibody staining in tissue sections. Two different markers were used separately on tissue sections to probe for the presence of muscle precursor cells. The unoperated side, a positive internal control, showed strong staining in the myotomes and in the dorsal and ventral muscle masses of the wing (Fig. 3, $A, C, E$ ). Embryos having muscleless wings showed neither CCM31A-nor 13F4-immunoreactivity in the

\section{$\leftarrow$}

the level of spinal segment 19 on control side of an experimental embryo. $A$, Myotome $(M)$ shows strong 13F4 immunoreactivity. $B$, Background fluorescence in same region on an adjacent section processed without 13F4. The few scattered brightly fluorescent cells are red blood cells. Identical photographic conditions for $A$ and $B$. DRG, dorsal root ganglion; $S$, spinal cord. Stage 28 embryo. Scale bar, $100 \mu \mathrm{m}$. 

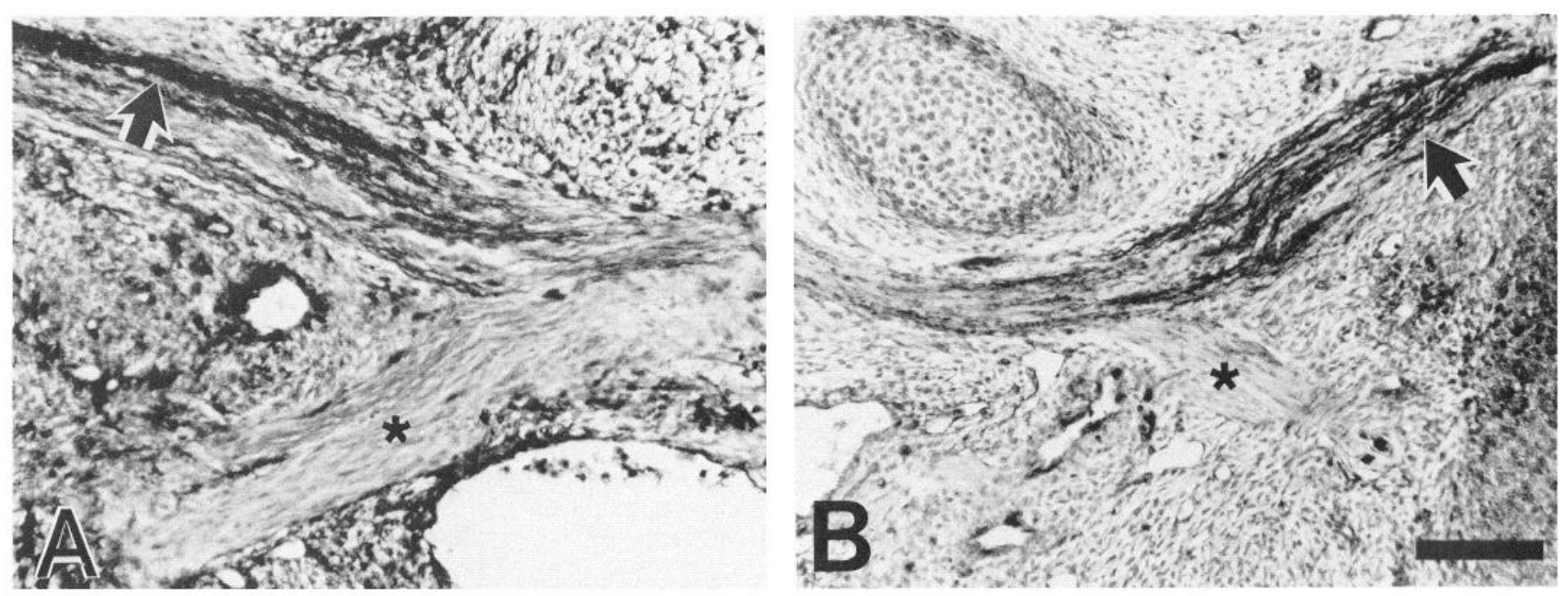

Figure 5. Retrogradely labeled axons in $\mathrm{n}$. brachialis superior and not in $\mathrm{n}$. brachialis inferior after a specific peripheral HRP injection into $\mathrm{n}$. radialis in a control and muscleless limb. $A$, Control side; $B$, muscleless side. Labeled axons were located exclusively in n. brachialis superior distal to dorsal/ventral decision region (arrows). No labeled axons were seen in the ventrally projecting $\mathrm{n}$. brachialis inferior (asterisk), confirming the specificity of the HRP injection. Stage 30 embryo. Scale bar, $100 \mu \mathrm{m}$.

presumptive myotomal or muscle mass regions (Fig. $3, B, D$, $F$ ). At the rostral and caudal borders of the region from which the somites had been surgically removed, a few muscle fibers were present, but these were well outside the range of the limbcontributing segments.

Is it possible that the experimental wings did not lack muscle fibers, but rather that the surgery produced a delay in expression of muscle specific problems? We think this is unlikely because muscle fibers were detected in experimental embryos at stages $28-30$ in which the somite removal was incomplete. In addition, muscleless limbs have been obtained as late as stage 36 , more than $5 \mathrm{~d}$ after the presence of muscle proteins could be detected in normal embryos. These older muscleless embryos were used for studies of motoneuron death (K. Phelan and M. Hollyday, unpublished observations). If muscle fiber differentiation was delayed but not abolished in our experimental embryos, it is likely that specific antibody binding would have been seen at these late stages on the operated side.

Successful experimental muscle removals were readily apparent. Myotubes were absent from the entire operated half of the brachial region, including the loss of myogenic cells from axial, proximal, and distal shoulder muscle masses. Four of 11 cases contained an individual or small (3-5) cluster of myotubes in the ventral body wall but were still included in the data set. Less complete removals showing a reduction but not total absence of the muscle component were eliminated if they contained numerous immunofluorescent cells in the regions of the pectoral and shoulder musculature.
In addition, a number of secondary characteristics accompanied the successful elimination of muscle from the wing. Muscleless cases lacked the somite-derived scapula (Chevallier, 1977) on the operated side and contained hemivertebrae within the operated zone (also see Bagnall et al., 1988). The absence of these elements caused the forelimb to be displaced dorsomedially to its normal position and the spinal cord to be scoliotic, with the convex side oriented toward the experimental side. Since the somites are responsible for imposing segmentation upon the spinal nerves (Detwiler, 1934; Keynes and Stern, 1984) and spinal ganglia (Rickmann et al., 1985), the experimental side of the muscleless embryos displayed unsegmented ventral roots. The sensory neurons did not form discrete DRG, but instead formed a continuous column of cells, typically $>1 \mathrm{~mm}$ in length, which extended throughout the operated region (see Tosney, 1988). We occasionally observed large neurons as far distal as the plexus which were interpreted as sensory neurons because of their staining properties. We were often able to trace fine cutaneous nerves from DRG neurons in our material despite the fact that they were unlabeled. Finally, the intermediate mesoderm was often removed along with the somites, eliminating the mesonephros.

\section{Specificity of motoneuronal projections}

Peripheral HRP injections were made into a total of 49 embryos during the course of this study. Of these, 24 failed to label a sufficient number of cells, 12 had injections into more than one peripheral nerve, and $36 \mathrm{had}$ a large number of muscle fibers on

Figure 6. Location of labeled motoneurons following injection of HRP into n. brachialis superior in normal and muscleless wings of an experimental embryo. $A$ and $B$, Retrogradely labeled motoneurons (white arrowheads) were correctly located in the lateral portion of the lateral motor column on both unoperated $(A)$ and somite removed $(B)$ sides. Dotted lines demarcate the medial borders of the lateral motor columns. Both photomicrographs were taken at the caudal level of spinal cord segment 14. The cluster of cells within the white matter of the spinal cord on the somite-removed side is composed of blood cells. $C$ and $D$, Distal musclature in the control wing and its absence in the experimental wing. 13F4 immunoreactivity was localized in the dorsal $(D)$ and ventral $(V)$ muscle mass derivatives in the unoperated wing $(C)$. No specific staining was seen on the somiteremoved side $(D)$, indicating the lack of muscle in this limb. Scale bars, $100 \mu \mathrm{m}$. Stage 30 embryo. 

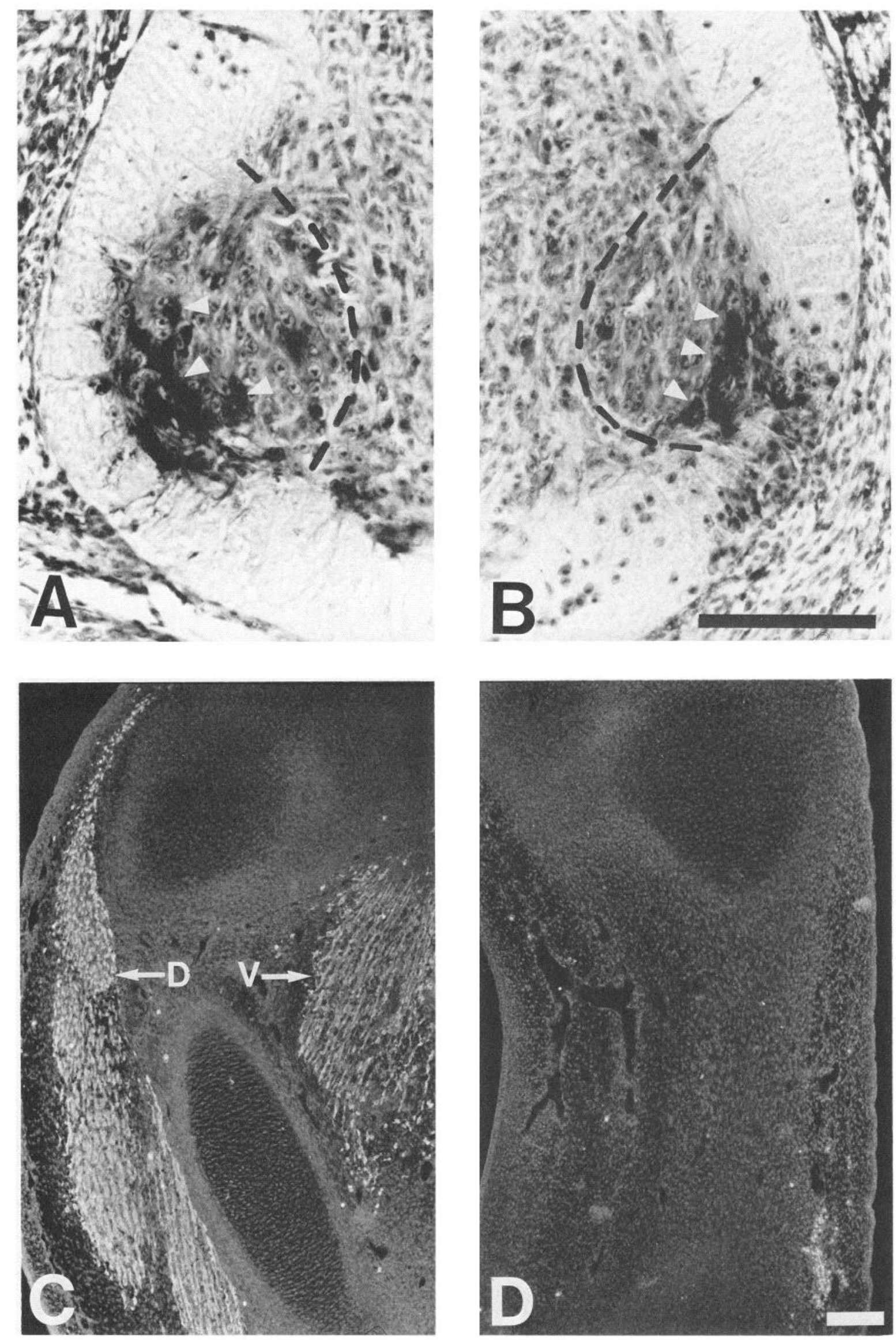


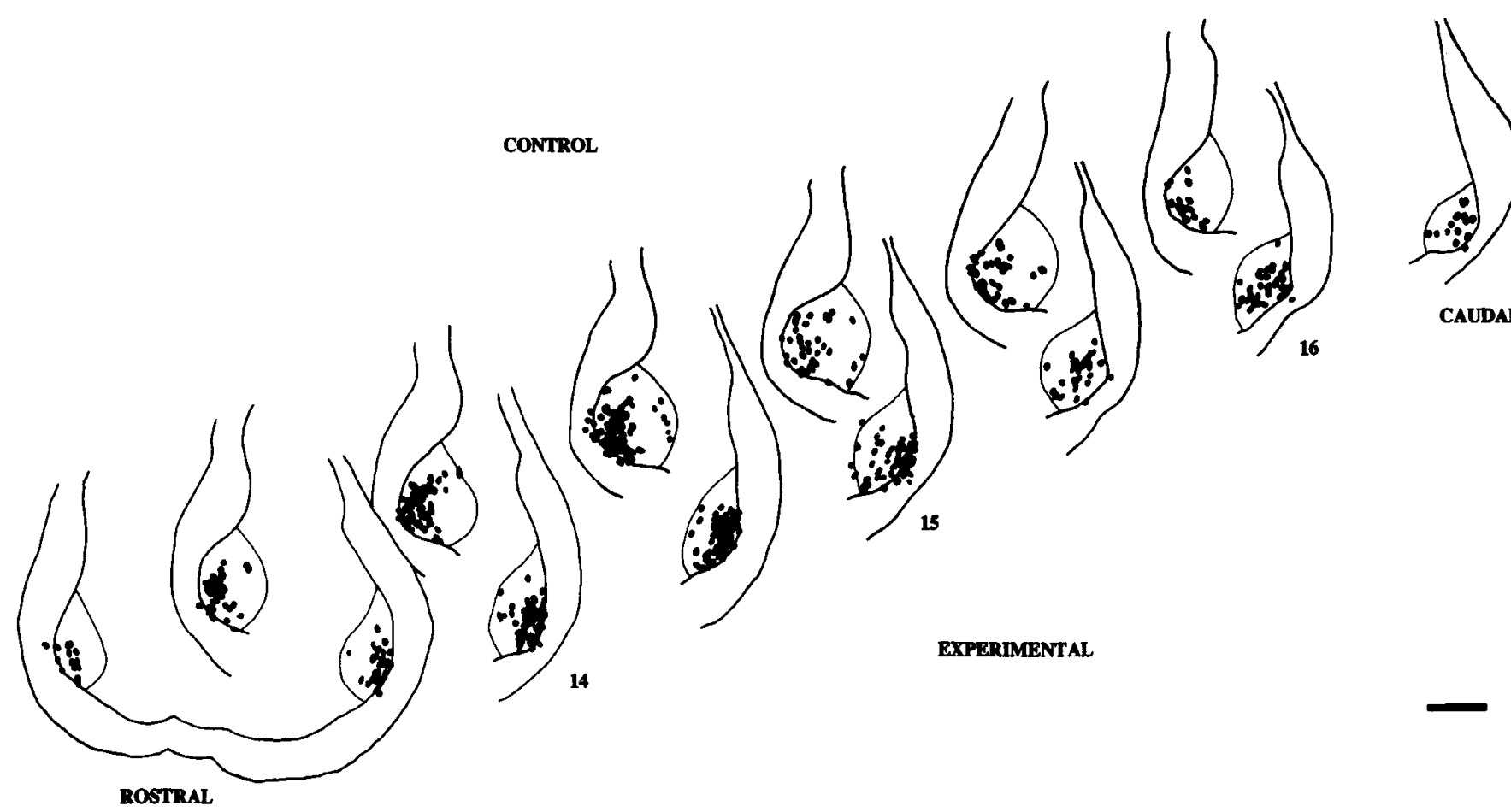

Figure 7. Reconstruction showing positions of labeled motoneurons following injection of HRP into n. brachialis superior in normal and muscleless wings. Numbers indicate ventral root positions on control side. Same embryo as Figure 6. Scale bar, $100 \mu \mathrm{m}$. Stage 30 embryo.

the experimental side. The specificity of the injection into a single peripheral nerve was verified by examination of transverse serial sections through the experimental wing. Embryos in which labeled axons were found in both dorsal and ventral peripheral nerves were eliminated from the experimental series. A total of 9 embryos had no muscle cells in the experimental limb and received specific HRP injections which labeled adequate numbers of spinal motoneurons. Four of these injections were made into $\mathrm{n}$. brachialis superior at the level of the divergence of axillaris and latissimus dorsi (see Fig. 1), and 5 were made into $\mathrm{n}$. brachialis inferior just distal to the divergence of pectoralis from the major ventral nerve trunk (see Fig. 1). Figure 5 shows the appearance of one injection site and the presence of HRP-labeled axons proximally and illustrates the specificity of the nerve injections used in this study.

Following bilateral injections of WGA-HRP into $\mathrm{n}$. brachialis superior, a nerve trunk which innervates dorsal muscle mass derivatives in the forearm, labeled motoneurons were found in the ventrolateral portion of the $1 \mathrm{mc}$ on both the normal and experimental sides (Figs. 6, 7). This is the normal position for motoneurons innervating dorsally derived muscles. Similarly, following injections of WGA-HRP into n. brachialis inferior, a nerve trunk which innervates ventral muscle mass derivatives in the forearm, labeled motoneurons were found almost exclu- sively in the dorsomedial half of the lmc bilaterally (Figs. 8, 9). This is the normal position for motoneurons innervating ventrally derived muscles.

As illustrated in the reconstructions (Figs. 7, 9), most of labeled motoneurons were appropriately positioned within the lmc. However, a small percentage of labeled cells were separated from the majority whose somas occupied contiguous positions. These separate cells were considered as incorrectly projecting motoneurons. Our operational definition of an errant cell was one whose labeled cell body lay in the medial-most portion of the lateral motor column after an injection into $\mathrm{n}$. brachialis superior, or one whose HRP-filled soma lay in the lateral-most portion of the lateral motor column after an injection into $n$. brachialis inferior. Table 1 summarizes the numbers of HRPlabeled motoneurons seen in individual cases. The numbers of labeled cells located in either the medial or lateral halves of the lateral motor column are tabulated separately. Following injection into a ventral nerve trunk, approximately $95 \%$ of the labeled cells were located medially within the lateral motor column. Comparison of the ratio of "inappropriately" positioned motoneurons to the total number of labeled motoneurons showed that the operated and unoperated sides were insignificantly different (Student's $t$-test). Following injection into a dorsal nerve trunk, nearly $90 \%$ of the labeled cells were located laterally

Figure 8. Location of labeled motoneurons following injection of HRP into $\mathrm{n}$. brachialis inferior in normal and muscleless wings of an experimental embryo. $A$ and $R$, Retrogradely labeled motoneurons (white arrowheads) were correctly located in the medial portion of the lateral motor column on both unoperated $(A)$ and somite removed $(B)$ sides. Dotted lines demarcate the medial borders of the lateral motor columns. Both photomicrographs were taken at the middle level of spinal cord segment 14 . The cluster of cells within the white matter of and ventrolateral to the spinal cord on the somite-removed side is composed of blood cells. $C$ and $D$, Distal musculature in the control wing and its absence in the experimental wing. 13F4 immunoreactivity was localized in the dorsal $(D)$ and ventral $(V)$ muscle masses in the unoperated wing $(C)$. No specific staining was seen on the somite-removed side $(D)$, indicating the lack of muscle in this limb. Scale bars, $100 \mu \mathrm{m}$. Stage 28 embryo. 

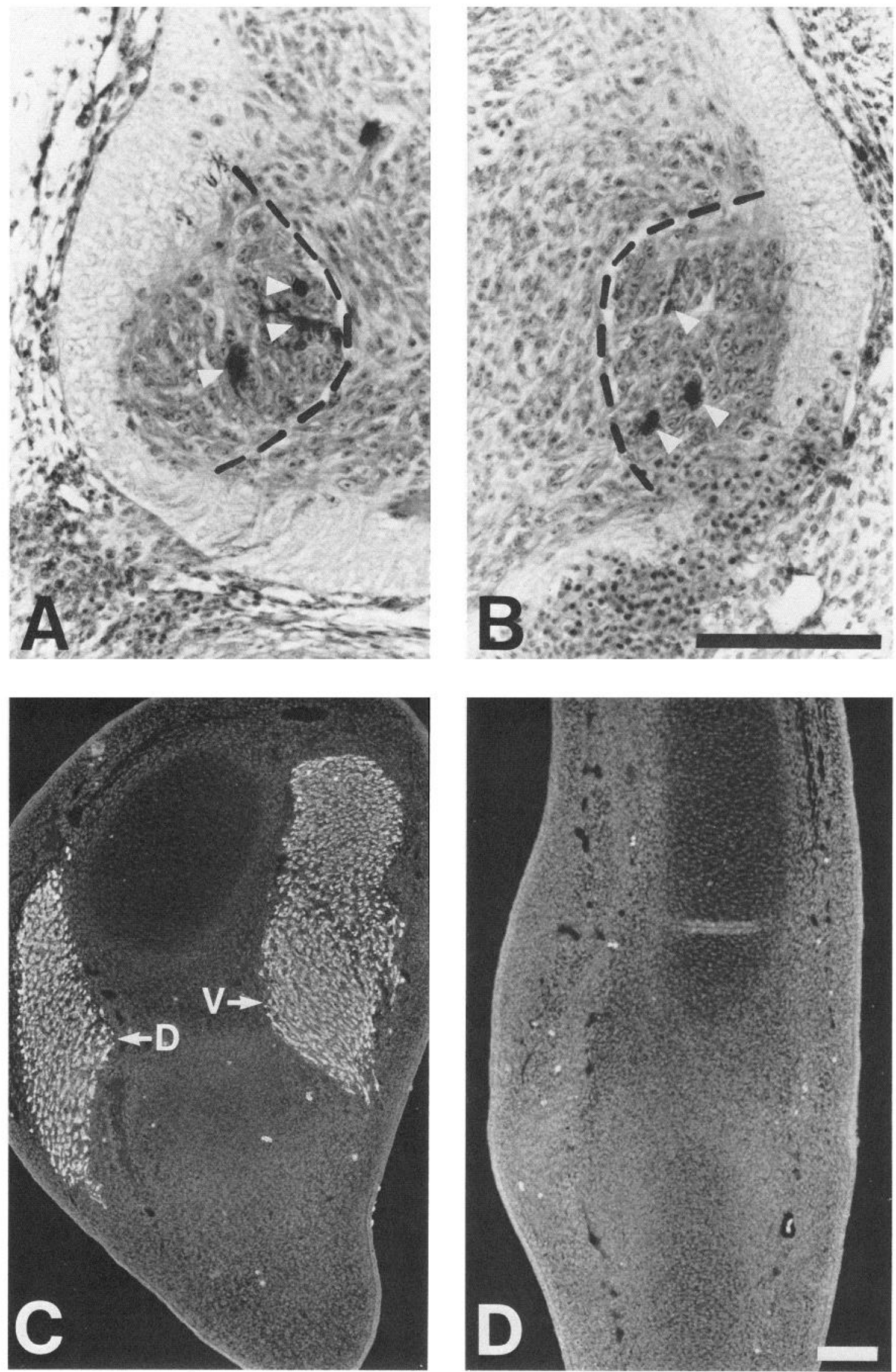


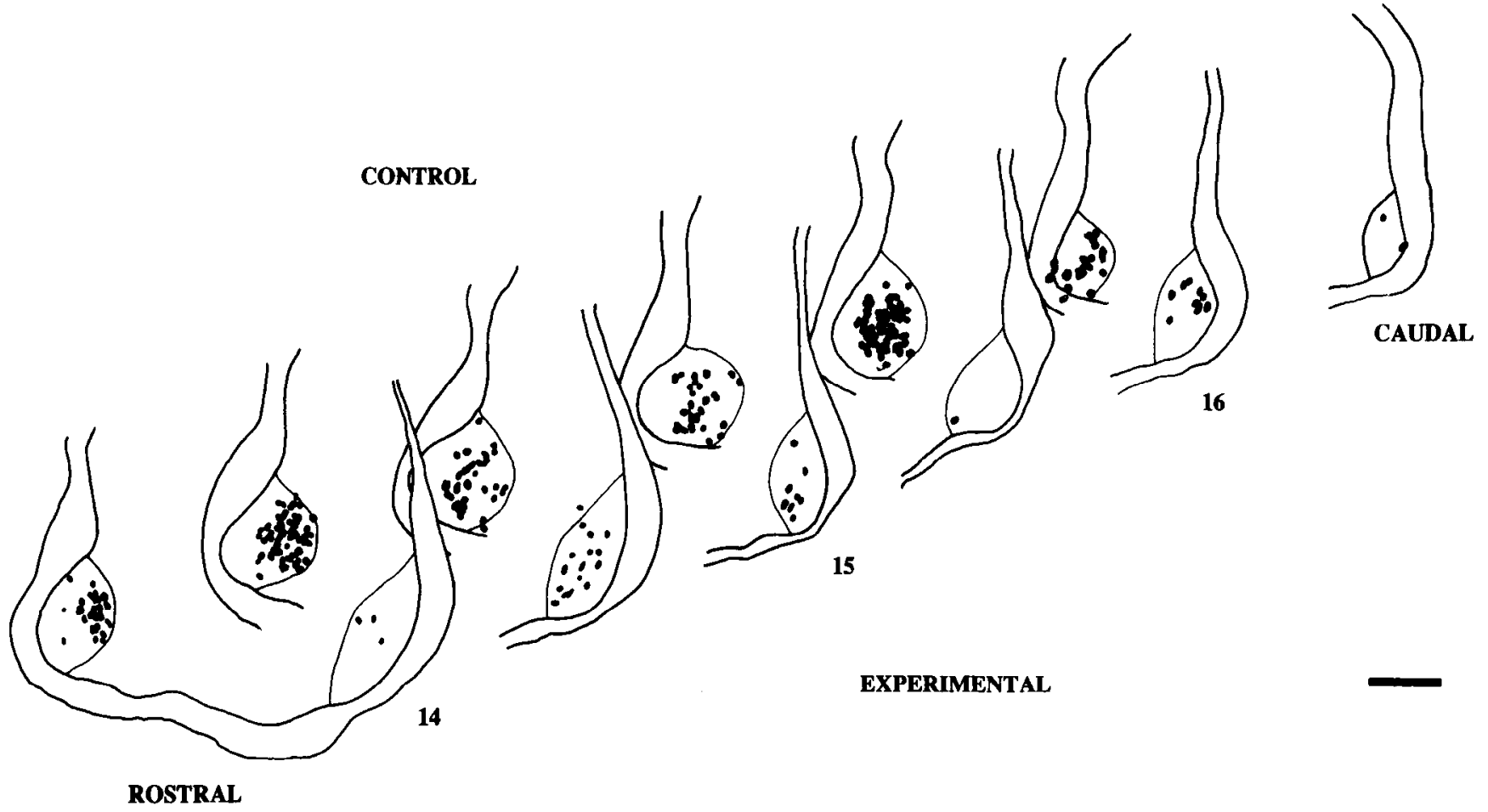

Figure 9. Reconstruction showing positions of labeled motoneurons following injection of HRP into $\mathrm{n}$. brachialis inferior in normal and muscleless wings. Numbers indicate ventral root positions on control side. Same embryo as Figure 8. Scale bar, $100 \mu \mathrm{m}$. Stage $28 \mathrm{embryo.}$

within the lateral motor column. Again, the difference between control and experimental sides was insignificant.

The numbers of labeled motoneurons varied considerably from case to case. It is unlikely that this reflects numerical differences in the numbers of motoaxons in different experimental cases, but rather differences in the percentage of axons that were labeled following a given injection. No qualitative size

\section{Table 1. Mediolateral positioning of HRP-labeled neurons after} somite removal

\begin{tabular}{|c|c|c|c|c|c|}
\hline \multirow[b]{3}{*}{ Case (ST) } & \multicolumn{2}{|c|}{ Unoperated side } & \multicolumn{3}{|c|}{ Operated side } \\
\hline & $\begin{array}{l}\text { No. labeled } \\
\text { MNs }\end{array}$ & No. & & eled & No. \\
\hline & $\bar{M}$ & & $\mathbf{M}$ & $\mathrm{L}$ & SNs \\
\hline
\end{tabular}

Ventral branch (n. brachialis inferior) injections

$\begin{array}{rrrrrrr}6-2(28) & 23 & 0 & 180 & 42 & 4 & 105 \\ 24-4(28) & 15 & 0 & 2 & 177 & 0 & 8 \\ 34-1(29) & 20 & 1 & 1 & 19 & 0 & 13 \\ 41-2(28) & 299 & 15 & 146 & 1172 & 82 & 141 \\ 254-4(28) & 298 & 13 & 361 & 32 & 5 & 136 \\ \text { Total } & 655 & 29 & 690 & 1442 & 91 & 403\end{array}$

Dorsal branch (n. brachialis superior) injections

$\begin{array}{lrrrrrr}43-2(30) & 0 & 4 & 43 & 9 & 48 & 9 \\ 94-3(28) & 0 & 13 & 47 & 0 & 116 & 75 \\ 238-1(29) & 3 & 44 & 705 & 0 & 23 & 146 \\ 244-3(30) & 52 & 384 & 1589 & 65 & 416 & 627 \\ \text { Total } & 55 & 445 & 2384 & 74 & 603 & 857\end{array}$

Abbreviations: ST, embryonic stage; $\mathrm{SN}$, sensory neurons; $\mathrm{MN}$, motoneurons; $\mathrm{M}$, medially positioned cells; L, laterally positioned cells. differences of the peripheral nerve trunks were noted among experimental cases at these stages.

Of the 9 embryos judged to have muscleless limbs by the above criteria, HRP-labeled motoneurons were found in the appropriate mediolateral position within the spinal cord in all cases. Subsequent to an injection into $\mathrm{n}$. brachialis superior, filled cell bodies were observed in the lateral portion of the $1 \mathrm{mc}$ $(n=4)$; injection into $\mathrm{n}$. brachialis inferior yielded labeled cells which were located in the medial portion of the $\operatorname{Imc}(n=5)$ (Table 1). In addition, cell bodies were always appropriately localed along the rostrocaudal axis of the experimental lmc. After an injection into $\mathrm{n}$. brachialis superior, laterally positioned labeled cell bodies were located in brachial segments containing motor pools which normally project to muscles located distal to the injection site (Fig. 10). After an injection into n. brachialis inferior, medially positioned labeled motoneurons were also located at segmental levels which normally project to distal muscles within the wing (Fig. 11).

The rostrocaudal distribution of the labeled cells for each of the 2 cmbryos illustrated in Figures 6-9 is plotted in Figures 10 and 11 . Labeled motoneurons are almost exclusively laterally positioned after an injection into $\mathrm{n}$. brachialis superior (Fig. 10) and almost exclusively medially positioned after an injection into $\mathbf{n}$. brachialis inferior (Fig. 11). Comparing the distribution of labeled cells on the unoperated and operated sides shows that brachial motoneurons reside in appropriate mediolateral posilions along the entire length of the lateral motor column after removal of the brachial somites and elimination of the wing musculature.

\section{Formation of muscle nerves in the absence of muscle cells}

In addition to examining the specificity of projections within major nerve trunks, we assessed the formation of muscle nerves 


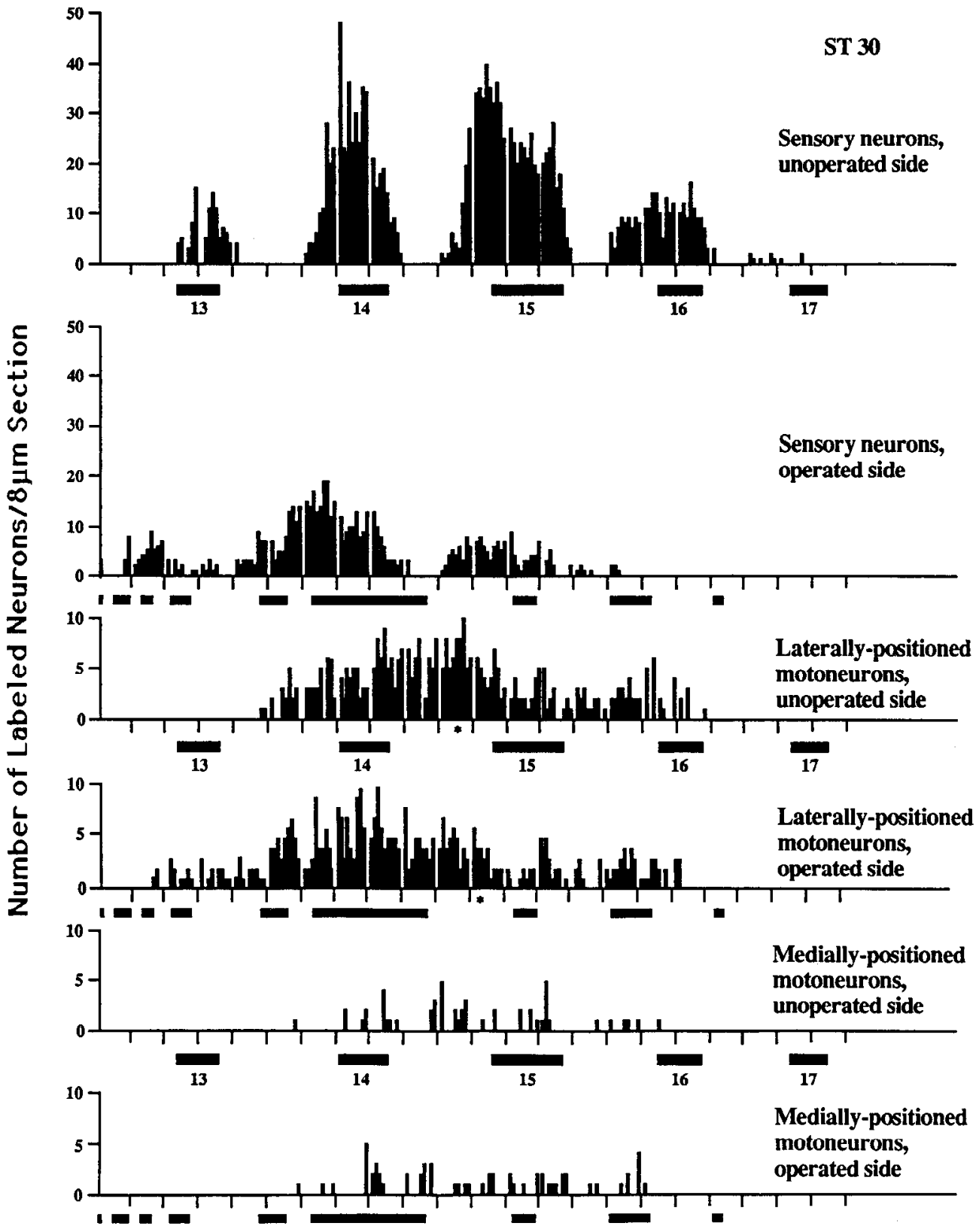

Figure 10. Histograms showing the rostrocaudal distribution of HRP-labeled neurons on control and muscleless sides after an injection into $n$. brachialis superior. Distribution of both labeled sensory and motor neurons is similar on unoperated and operated sides. Solid bars beneath the abscissa indicate the ventral roots; downward ticks indicate sections examined for the presence of muscle. Asterisks indicate sections shown in Figure $6, A, B$. Note that segmentation of the ventral roots and sensory ganglia is disrupted on the experimental side. in muscleless limbs. In normal chicks, the muscle nerves in the wing have begun to form by stage 26 , with the full complement of muscle nerves present by stage 28 in the proximal shoulder and stage 31 in the forearm (Sullivan, 1962; Roncali, 1970; Swanson and Lewis, 1982).

Identifiable muscle nerves from major nerve trunks were reliably seen in histological sections on the somite removed side in all examined cases. At early stages, these nerves were of normal size and length and were located at sites where nerves to specific muscles normally form in chick wings (Fig. 12). Only undifferentiated mesenchymal cells of unidentifiable cell type were present around the nerves and their areas of termination. The presence of muscle fibers in the vicinity of the muscle nerves that we observed was carefully ruled out by examination of the sections reacted for muscle immunoreactivity (Fig. 13). We did occasionally see a stray fiber or cluster of cells in the experimental limb, but they were never closer than $200 \mu \mathrm{m}$ to the most proximal muscle nerves formed. As stated previously, we were careful to exclude cases which showed incomplete removal of muscles. Table 2 summarizes the observations of proximal muscle nerves in muscleless wings.

Although muscle nerves were present in both normal and experimental wings, they differed in their histological appearance between normal and muscleless wings. The presence of muscle resulted in a muscle nerve bearing a more elaborate terminal structure, which was tufted and fanlike (Fig. 12C). Endings within the target field were dispersed and intramuscular nerve branches were often visible at older stages. In contrast, muscle nerves ending in muscle-free regions appeared unbranched and blunt (Fig. 12D). Higher-order nerve branching within the target field was most thoroughly examined within the pectoral muscle. Normally, intramuscular nerve branches initially form at stage 28-29 (Swanson and Lewis, 1982; M. Hollyday, unpublished observations). After the muscle nerve reach- 
Figure 11. Histograms showing the rostrocaudal distribution of HRP-labeled neurons on control and muscleless sides after an injection into $\mathrm{n}$. brachialis inferior. Distribution of labeled neurons is similar on unoperated and operated sides. Solid bars beneath the abscissa indicate the ventral roots; downward ticks indicate sections examined for the presence of muscle. Asterisks indicate sections shown in Figure $8, A, B$. Note that segmentation of the sensory ganglia is disrupted on the experimental side.

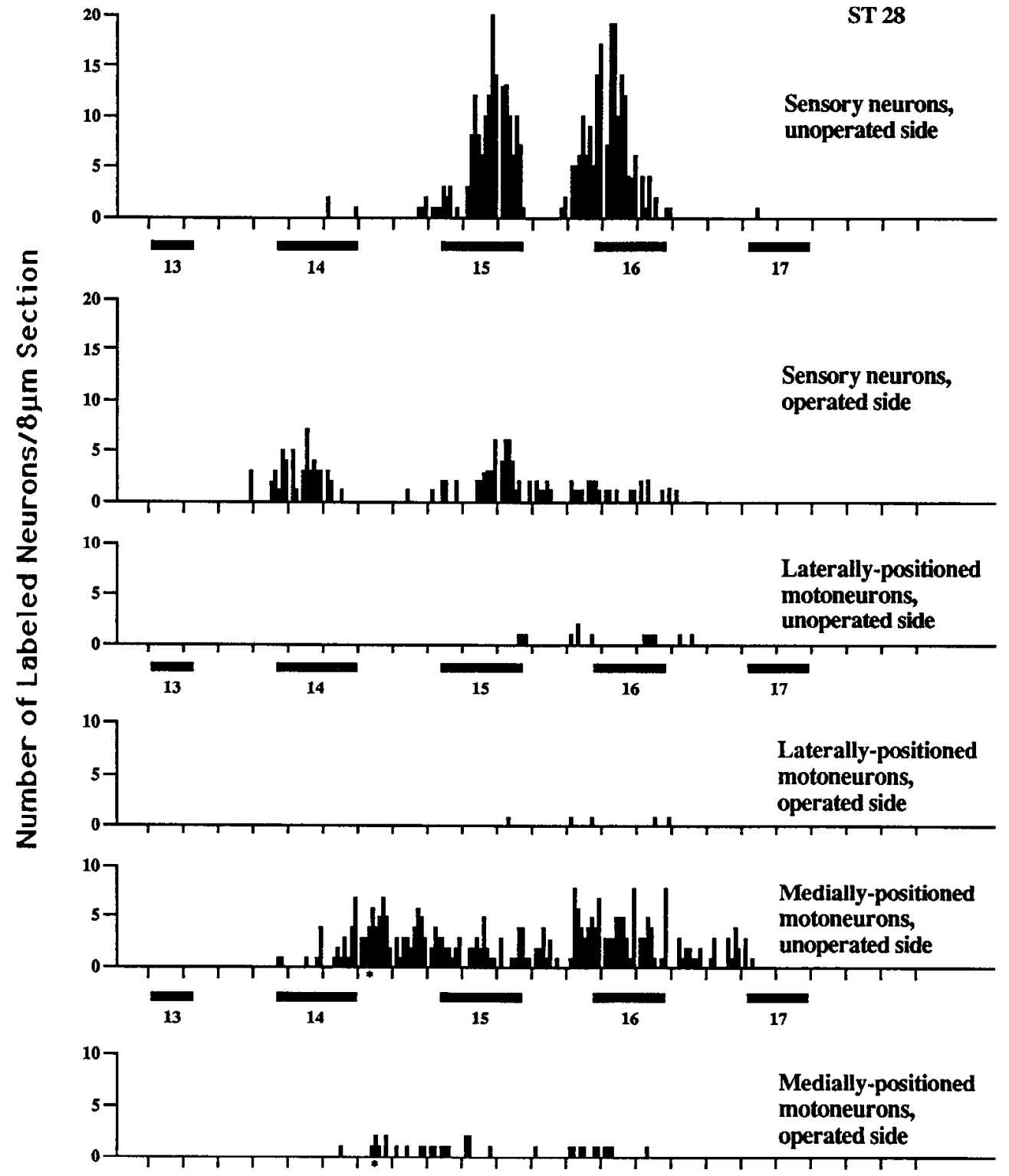

es the target, it bifurcates within the pectoral muscle, sending a large fascicle of axons rostrally and another caudally. These second-order nerve branches were not observed in muscleless limbs.

In older experimental embryos, muscle nerves to proximal muscles were still visible, but they were considerably smaller than at earlier stages. This diminution corresponded with the progressive motoneuron loss at these stages in the absence of muscle (K. Phelan and M. Hollyday, unpublished observations). At stage 36, the oldest stage examined, only small remnants of muscle nerves were visible. Most of the innervation to the wing in older embryos was composed of sensory innervation. The cutaneous nerve that was examined in detail, the cutaneous nerve from triceps brachii, was large and branched, and extended to the skin. The ventral roots were tiny in comparison to the spinal nerves, suggesting that the majority of axons was contributed by sensory neurons. This is also consistent with motoneuron counts (K. Phelan and M. Hollyday, unpublished observations).

\section{Lack of axial nerves in the absence of myotomal muscle}

Axial muscles positioned dorsal and lateral to the spinal column are normally innervated by motoneurons whose cell bodies lie in the median motor column ( $\mathrm{mmc}$ ) of the spinal cord. The axons from these neurons exit the spinal cord at stage 17 via the ventral root and project dorsally to innervate the embryonic

Figure 12. Muscle nerves are formed in the absence of muscle cells. Bright-field photomicrographs showing muscle nerves in unoperated ( $A$, $C$, $E, G)$ and musclcless $(B, D, F, H)$ wings. Nerves have formed near the muscles shown in Figure 13 both on the unoperated side and at equivalent levels on the contralateral muscle-free side. $A$ and $B$, n. axillaris, stage $28 ; C$ and $D$, n. supracoracoideus, stage $29 ; E$ and $F$, n. pectoralis, stage 29 ; $G$ and $H$, n. biceps brachii, stage 30 . Arrowheads indicate muscle nerves. Scale bars, $100 \mu \mathrm{m}$. 

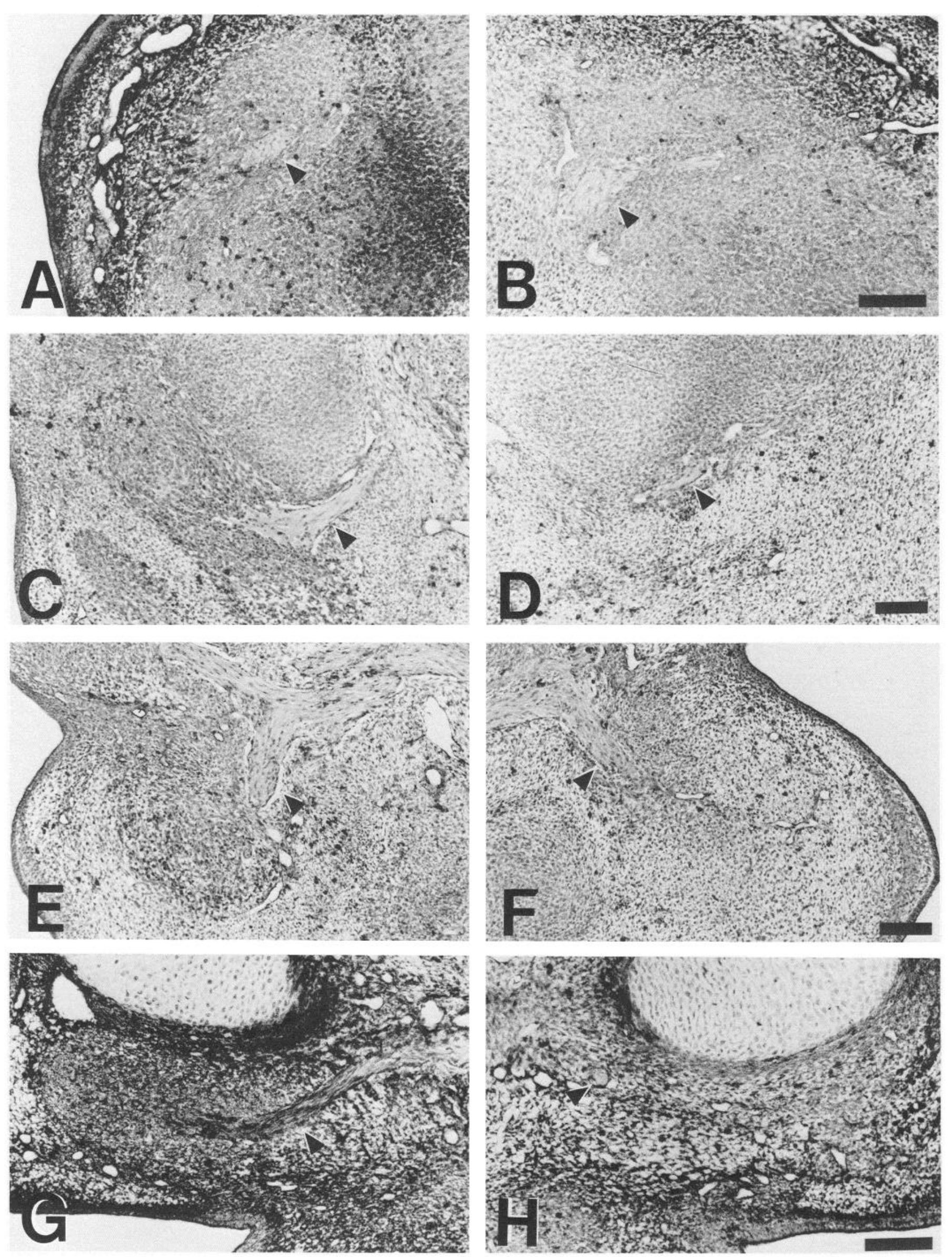

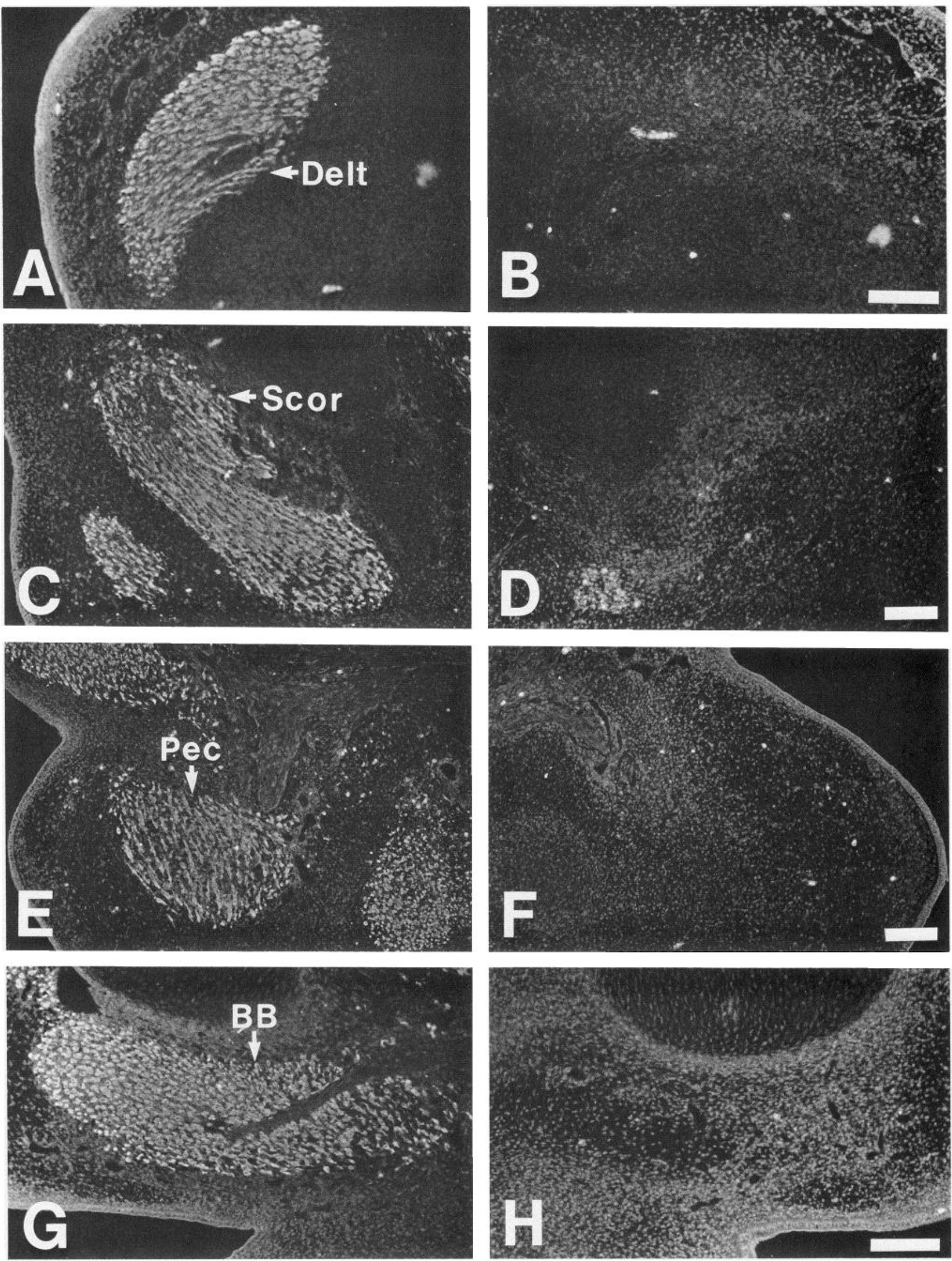

Figure 13. 13F4-immunohistochemical verification of muscle removal in embryos shown in Figure 12. 13F4 immunoreactivity is seen on the control $(A, C, E, G)$ side but not on the experimental muscleless $(B, D, F, H)$ side in closely adjacent sections. This confirms that myotubes are present in muscle precursors on the unoperated sides but are absent in similar regions on the experimental, somite-removed side. Scale bars, 100 $\mu \mathrm{m}$. Muscle abbreviations: BB, biceps brachii; Delt, deltoideus; Pec, pectoralis; Scor, supracoracoideus. 
myotome. Later in development, the myotomal musculature is cleaved and forms distinct axial muscles. These muscles are innervated by mmc motoneurons whose axons form a characteristic pattern of innervation. Between stages 28 and 30, the stages included in this study, axons normally traverse the entire dorsoventral extent of the somitically derived axial musculature in brachial and thoracic segments. Just distal to the confluence of the ventral root and dorsal root ganglion fibers in the spinal nerve, axons diverge from the spinal nerve and ascend along the medial face of the myotome in the anterior portion of each segment to form the dorsal ramus (see Tosney, 1987). The remaining axons continue distally to the base of the myotome, where they separate into 2 nerves which project along the medial and lateral faces of the costal cartilage as ventral rami.

In contrast to the findings in the limb, myotomal nerves were not observed in segments from which somites had been removed. We looked for them in both brachial and rostral thoracic segments which were devoid of axial muscle. The thoracic segments were muscleless as a result of the removal of segmental plate to prevent regulation and repopulation of the wings by nearby segments. As compared to the unoperated side of the embryo, the characteristic nerve branching patterns produced by axial motoneurons were not observed; dorsal rami were not present, nor were the more ventrally directed nerves which normally innervate the flank. At the surgical borders where axial muscles reappeared, dorsal rami were not seen in operated, muscle-free segments. In the next adjacent segment, however, axial nerves formed normally in the presence of myotomal muscle, ascending the medial face of the myotome and penetrating the muscles with laterally oriented branches. We are confident that if epaxial muscles adjacent to the somite-deleted segments had been supplied by even a small nerve from the segment in which the somite had been removed, it would have been detected because we were able to see fine, unlabeled cutaneous nerves emerging from sensory neurons in operated segments.

In muscleless segments, nerve fibers were observed in the ventral roots and projected for varying distances distally. Brachially, motor axons exited to innervate the wing. Thoracically, axons emerged from the ventral spinal cord, only to end bluntly after growing a distance of approximately $200 \mu \mathrm{m}$ laterally. The normal separation into dorsal and ventral rami was not observed. Some axons projected to the prevertebral sympathetic chain ganglia, which formed in a normal position despite the removal of the somites. These nerve fibers most likely come from the preganglionic sympathetic cells, Terni column neurons (Terni, 1924) which are present in these spinal segments (LeviMontalcini, 1950).

Small fascicles of nerve fibers were infrequently seen in the mesenchymal tissue of the muscleless lateral body wall. These axons could be traced back to clusters of sensory neurons adjacent to the spinal cord and were thus sensory. The sensory nerves did not conform to the normal, gross anatomical projection pattern in the flank of the embryo.

In somite-removed segments, the spinal cords did contain motoneurons within the median motor columns. However, as noted above for the lateral motor columns, the median motor columns also appeared to be depleted. No cell counts were made to quantify this observation.

\section{Formation of spinal ganglia and position of sensory neurons}

Neural segmentation is imposed by the sclerotome (Detwiler, 1934), which is somite derived. Somite removal from brachial

\begin{tabular}{|c|c|c|c|c|c|c|}
\hline \multirow[b]{2}{*}{ Stage } & \multicolumn{3}{|c|}{$\begin{array}{l}\text { To ventrally derived } \\
\text { muscles }\end{array}$} & \multicolumn{3}{|c|}{$\begin{array}{l}\text { To dorsally derived } \\
\text { muscles }\end{array}$} \\
\hline & Scor & Pec & $\mathrm{BB}$ & LD & $A x$ & TriB \\
\hline 28 & $3 / 3$ & $3 / 3$ & $1 / 3$ & $3 / 3$ & $3 / 3$ & $2 / 3$ \\
\hline 29 & $3 / 3$ & $3 / 3$ & $2 / 3$ & $3 / 3$ & $3 / 3$ & $2 / 3$ \\
\hline 30 & $3 / 3$ & $3 / 3$ & $3 / 3$ & $3 / 3$ & $2 / 3$ & $3 / 3$ \\
\hline Total & $9 / 9$ & $9 / 9$ & $6 / 9$ & $9 / 9$ & $8 / 9$ & $7 / 9$ \\
\hline
\end{tabular}

Abbreviations: Ax, axillaris; BB, biceps brachii; LD, latissimus dorsi; Pec, pectoralis; Scor, supracoracoideus; TriB, triceps brachii.

segments, primarily to eliminate muscle from the wing, also resulted in DRGs with disrupted or abolished segmentation (see Tosney, 1988). In general, sensory neurons on the operated side failed to form spinal ganglia which conformed to the rostrocaudal borders maintained by the contralateral unoperated side. Instead, they formed extended columns of cells adjacent to the spinal cord which lay upon similarly dis-segmented ventral roots. The cells of these spinal ganglia formed central projections which entered the spinal cord via a normally located dorsal root entry zone. Centrally directed sensory fibers took circuitous routes to attain these connections, initially growing along the spinal nerve and then branching back toward the spinal cord but always entering the spinal cord at the normal level and producing the oval bundle of His, the rudimentary dorsal funiculus, in its proper location.

Sensory neurons often migrated distally into the wing and were commonly found in ectopic locations along peripheral nerves. Similar observations have been previously reported by Landmesser and Honig (1986) and Tosney (1988) following different surgical manipulations. These cells could be readily identified as sensory neurons using cytological criteria; they were large, containing a voluminous nucleus, prominent nucleolus, and densely staining basophilic cytoplasm. The aberrantly located sensory neurons projected axons both peripherally and centrally, as demonstrated by the presence of HRP-reaction product after major nerve trunk injections.

Sensory neurons were frequently labeled following peripheral nerve injections (Table 1). Many of these were located in the proximal unsegmented ganglia, but some peripherally located ectopic sensory neurons were labeled as well. Since neuronal position cannot be used in sensory ganglia for target prediction as in the lateral motor column (Honig, 1982), it cannot be determined whether the projections made by these neurons are correct or incorrect using the present techniques. However, the rostrocaudal distribution of labeled sensory neurons did parallel that of the limb motoneurons (Figs. 10, 11), as in normal development (Honig, 1982).

\section{Discussion}

Pathway selection in muscleless wings: dorso/ventral decision Motor axons selected appropriate pathways distal to the wing plexus despite the early removal of somitic tissues which give rise to muscle precursor cells. This result strongly and directly suggests that motor axon guidance cues operant at and just distal to the plexus are unrelated to the presence of target. This conclusion agrees with that of Tosney and Landmesser (1984), who have also reported observing appropriate sorting out at the crural plexus of the chick hindlimb in embryos with severe hindlimb bud removals. 
A small (5-10\%) percentage of errors was detected on the somite-removed side, but these were similar to and insignificantly different from those also detected on the unoperated side. We consider these errors to be naturally occurring and unrelated to the removal of the target on the experimental side. Other investigators have also illustrated such errors in normal embryos at similar stages prior to naturally occurring motoneuronal death (see Landmesser, 1978; Ferguson, 1983). We have chosen this interpretation because of the attention paid to the specificity of our major nerve trunk injections (Fig. 5) and because the axons were solidly labeled from the injection site and could be traced in serial sections. Injections which labeled axons in unintended nerves were eliminated from the experimental series.

In muscleless wings, the localization of motor pools along the rostrocaudal axis in these studies was appropriate on a coarse level, with distally projecting cells lying within middle-to-caudal segments of the brachial lateral motor column. These motoneuronal locations agree with studies conducted on normal chickens of hatchling or adult ages (Ohmori et al., 1982; Straznicky and Tay, 1983; M. Hollyday and R. Jacobson, unpublished observations). An injection into $n$. radialis within a muscleless wing at the level of $n$. triceps brachii and $n$. axillaris divergence labeled motoneurons from caudal segment 13 to caudal segment 16 . These cells were in positions consistent with those in motor pools for muscles lying at and distal to the injection sitc. Injcctions into $\mathrm{n}$. brachialis inferior immediately distal to the divergence of $n$. biceps brachii yielded analogous results.

From these studies we conclude that muscle cells are not necessary for accurate motor axon guidance into the periphery along the routes of major nerve trunks. Axons are capable of making an appropriate choice at the dorsal/ventral branch point in the absence of their target. These studies imply that cues derived from the somatopleural lateral plate mesoderm, the second contributor to the limb tissue, are sufficient to guide growing motor axons during their highly patterned initial outgrowth into the wing bud. This implication has been given recent experimental support by the work of Lance-Jones (1989) which showed that a shift of the lateral plate mesoderm along the anterior-posterior axis of the embryo produced a like shift in the segmental contributions to the typical nerve pattern.

\section{Wing muscle nerve formation}

An unanticipated finding was that in contrast to what was reported by Lewis et al. (1981), muscle nerves were present in muscleless wings. Nerves clearly diverged from the major nerve pathways in each of 9 muscleless cases. Older embryos showed a more complete nerve pattern than younger ones, consistent with the fact that the muscle nerve branching pattern is normally more developed at these stages. Some of the nerves supplied several muscles (e.g., n. axillaris and the common latissimus dorsi nerve) or a complex multiheaded muscle (e.g., n. pectoralis and $n$. triceps), but nerves to single muscles were also seen (n. biceps brachii). Of the nerves observed in muscleless wings, only $n$. axillaris and $n$. triceps normally have a cutaneous component (Fig. 1). While our methods could not determine whether the axons were motor, or sensory (most likely both), it is clear that discrete muscle nerves were routinely present in our material.

Our conclusions are at odds with those of Lewis et al. (1981). It should be noted that we assessed the presence of a largely different subpopulation of muscle nerves than did Lewis et al.
(1981). Table 2 and Figure 12 document the presence of nerves to proximal wing muscles, while the other group reported primarily on nerves to further distal muscles, since the silver staining of the nerves in the shoulder region was unreliable. However, both studies examined one pair of muscles in common, biceps brachii and triceps brachii; when these data are compared, the discrepancy still exists.

The most likely explanation of the conflict lies in the different methods used to produce muscleless wings. In our study, the somites were removed surgically, taking care not to damage either the neural tube or lateral plate. It is probable that the $\mathrm{X}$-rays used by I ewis and his colleagues may have spread and sufficiently damaged cells adjacent to the somites to prevent the formation of muscle nerves. Either the neural tube or somatopleure could have suffered radiation damage which went undetected in those studies.

In older embryos, the degeneration of motoneurons and their axons secondary to the removal of the target muscles provides an additional explanation for the absence of muscle nerves. It is well established that motoneuron survival depends on the presence of muscle target tissue (Hamburger, 1958; Laing, 1982). We have confirmed the depletion of muscle nerves at older stages and have studied cell death among motoneurons projecting to muscleless wings. In older embryos the depletion of muscle nerves corresponds well with motoneuron death $(\mathrm{K}$. Phelan and M. Hollyday, unpublished observations).

\section{Axial muscle nerve formation}

Although we routinely identified proximal muscle nerves in muscleless wings, we failed to see myotomal nerves at brachial and trunk levels in the absence of the axial musculature. The trunk segments caudal to the wing were muscleless due to the removal of additional somites to prevent regulation from nearby rostrocaudal levels. At the stages examined, dorsal rami were never seen in somite removed segments, whether brachial or thoracic, even in the segments bordering on muscle-containing segments. These results suggest that some somite derivative is required for the formation of myotomal nerves.

In previous studies, Tosney $(1987,1988)$ selectively removed varying amounts of somitic tissue in one or more segments and observed that the dorsal ramus formed only when muscle fibers were present in the samc or the adjacent myotomc. The interpretation given these results was that formation of the dorsal ramus normally depends on response to a chemotactic cue from myotomal muscle, and that the sclerotome is not required. Our observation that the dorsal ramus was not present in the absence of myotomal muscle is in agreement with these reports. In contrast to Tosney, we did not observe dorsal rami in segments immediately adjacent to unoperated segments. Since our embryos were at stages similar to those examined by Tosney, this cannot account for the difference. The explanation most likely lies in the nature of the initial surgical manipulation. We removed the entire somite, including all dermamyotomal and sclerotomal components. The presence of hemivertebrae and the poor neural segmentation observed in operated segments is consistent with the removal of the sclerotome. We think that the explanation for the absence of a dorsal ramus in our material was the complete removal of the sclerotome. If sclerotome was not necessary, and chemotactic cues from nearby epaxial muscles were sufficient, we would have expected to see dorsal rami in operated segments adjacent to unoperated ones, and we did not. However, since we did not examine embryos at early stages, 
we cannot exclude the possibility that dorsal rami formed but degenerated as a result of the absence of the myotome. We do not favor this explanation since some motoneurons were present in the median motor columns of brachial and thoracic segments, but like the lateral motor columns, these populations appeared depleted. The possibility of median motor column cell death induced by target removal was not investigated by Tosney (1987, 1988).

\section{Roles of muscle in limb innervation}

Taken together, these results indicate that both the program for nerve pattern formation, as well as the cues used by motor neuron axons to sort out appropriately at the plexus and grow into the correct peripheral trunks, do not require the presence of muscle fibers anywhere along the pathway. Rather, they strongly implicate other components derived from the lateral plate, such as epimysial, perimysial or other cell types, in these roles. Axons are capable of making an appropriate pathway choice at the dorsal/ventral decision region at the plexus in the absence of muscle fibers. The rostrocaudal distribution of labeled moloneurons was also unchanged in muscleless wings. Since we observed the formation of muscle nerves in our material, it seems likely that the guidance cues necessary for specific motor projections are similarly independent of the muscle fibers, but single muscle nerves were not injected in this study to confirm this point directly. These observations imply that cues derived from the somatopleural lateral plate mesoderm, the second contributor to the limb tissue, are sufficient to guide growing motor axons during their highly patterned initial outgrowth into the wing bud.

The role of somitically derived cells in the wing seems to be to promote intramuscular nerve branching (see also Dahm and Landmesser, 1988) and cell survival (K. Phelan and M. Hollyday, unpublished observations), but not the initial formation of muscle nerves (Lewis et al., 1981). The marked difference between muscle nerves in muscleless versus normal wings was apparent at young stages prior to muscle mass cleavagc. The differences in intramuscular branches were even more apparent at older stages. These observations are consistent with the idea that muscle fibers promote axonal branching prior to synapse formation. In the absence of the muscle fibers, muscle nerves are formed, but higher-order branching fails to occur.

In summary, the results show that myotubes are not necessary for motor axonal guidance within the major nerve trunks. Nor are they required for the formation of the pattern of muscle nerves within the proximal chick wing. By inference, cells derived from the other developmental contributor to the limb tissues, the somatic mesoderm, are sufficient in providing the peripheral cues which govern these embryonic processes.

\section{References}

Adams JC (1981) Heavy metal intensification of DAB-based HRP reaction product. J Histochem Cytochem 29:775.

Bagnall KM, Saunders EJ, Higgins SJ, Leam H (1988) The effects of somite removal on vertebral formation in the chick. Anat Embryol 178:183-190.

Beresford B (1983) Brachial muscles in the chick embryo: the fate of individual somites. J Embryol Exp Morphol 77:99-116.

Chevallier A (1977) Origine des ceintures scapulaires et pelviennes chez l'embryon d'oiseau. J Embryol Exp Morphol 42:275-292.

Chevallier A, Kieny M, Mauger A (1977) Limb-somite rclationship: origin of the limb musculature. J Embryol Exp Morphol 41:245-258.

Christ B, Jacob HJ, Jacob M (1977) Experimental analysis of the origin of the wing musculature in avian embryos. Anat Embryol 150:171186.

Dahm LM, Landmesser LT (1988) The regulation of intramuscular nerve branching during normal development and following activity blockade. Dev Biol 130:621-644.

Detwiler SR (1934) An experimental study of spinal nerve segmentation in Amblystoma with reference to the plurisegmental contribution to the brachial plexus. J Exp Zool 67:395-441.

Ferguson BA (1983) Development of motor innervation of the chick following dorsal-ventral limb bud rotations. J Neurosci 3:1.760-1772.

Hamburger V (1958) Regression versus peripheral control of differentiation in motor hypoplasia. Am J Anat 102:365-410.

Hamburger V, Balaban M (1963) Observations and experiments on spontaneous rhythmical behavior in the chick embryo. Dev Biol 7: 533-545.

Hamburger V, Hamilton HL (1951) A series of normal stages in the development of the chick embryo. J Morphol 88:49-92.

Hollyday M (1983) Development of motor innervation of chick limbs. In: Limb development and regeneration. Part A (Fallon JF, Caplan AI, eds), pp 183-193. New York: Liss.

Hollyday M, Hamburger V (1977) An autoradiographic study of the formation of the lateral motor column in the chick embryo. Brain Res 132:197-208.

Honig MG (1982) The development of sensory projection patterns in embryonic chick hind limb. J Physiol (Lond) 330:175-202.

Keynes RJ, Stern CD (1984) Segmentation in the vertebrate nervous system. Nature 310:786-789.

I aing NG (1982) Timing of motoneuron death in the brachial and lumbar regions of the chick embryo. Dev Brain Res 5:181-186.

Lance-Jones C (1989) Axon guidance in the limb of the chick embryo: the role of non-neuronal tissues in providing specific cues. In: The assembly of the nervous system (Landmesser L, ed), pp 167-187. New York: Liss.

Landmesser L (1978) The development of motor projection patterns in the chick hind limb. J Physiol (Lond) 284:391-414.

Landmesser L, Honig MG (1986) Altered sensory projections in the chick hind limb following the early removal of motoneurons. Dev Biol 118:511-531.

Levi-Montalcini R (1950) The origin and development of the visceral system in the spinal cord of the chick embryo. J Morphol 86:253284.

I ewis J, Chevallier A, Kieny M, Wolpert L (1981) Muscle nerve branches do not develop in chick wings devoid of muscle. J Embryol Exp Morphol 64:211-232.

Ohmori Y, Watanabe T, Fujioka T (1982) Localization of the motoneurons innervating the forelimb muscles in the spinal cord of the domestic fowl. Zbl Vet Med C Anat Histol Embryol 11:124-137.

Oppenheim RW, Majors-Willard C (1978) Neuronal cell death in the brachial spinal cord of the chick is unrelated to the loss of polyneuronal innervation in wing muscle. Brain Res 154:148-152.

Phelan K, Hollyday M (1986) Pathway selection in muscleless chick limbs. Soc Neurosci Abstr 12:1210.

Rickmann M, Fawcett JW, Keynes RJ (1985) The migration of neural crest cells and the growth of motor axons through the rostral half of the chick somites. J Embryol Exp Morphol 90:437-455.

Roncali I. (1970) The hrachial plexus and the wing nerve pattern during early developmental phases in chicken embryos. Moritore Zool Ital 4:81-98.

Rong P-M, Ziller C, Pena-Melian A, LeDouarin NM (1987) A monoclonal antibody specific for avian early myogenic cells and differentiated muscle. Dev Biol 122:338-353.

Stemberger LA (1979) The unlabeled antibody peroxidase-antiperoxidase (PAP) method. In: Immunocytochemistry, pp 104-169. Englewood Cliffs, NJ: Prentice-Hall.

Straznicky C', Tay D (1983) The localization of motoneuron pools innervating wing muscles in the chick. Anat Embryol 166:209-218.

Sullivan GE (1962) Anatomy and embryology of the wing musculature of the domestic fowl (Gallus). Aust J Zool 10:458-518.

Swanson GJ, Lewis J (1982) The timetable of innervation and its control in the chick wing bud. J Embryol Exp Morphol 71:121-137.

Sweeney LJ, Clark WA, Umeda PK, Zak R, Manasek FJ (1984) Immunofluorescence analysis of the primordial myosin detectable in embryonic skeletal muscle. Proc Natl Acad Sci USA 81:797-800.

Sweeney LJ, Kennedy JM, Zak R, Kokjohn K, Kelley SW (1989) Evidence for expression of a common myosin heavy chain phenotype in 
future fast and slow skeletal muscle during initial stages of avian embryogenesis. Dev Biol 133:361-374.

Terni T (1924) Richerche anatomiche sul sistema nervosa autonomo degli uccelli. Arch Ital Anat Embr 20:433-510.

Tosney KW (1987) Proximal tissues and patterned neurite outgrowth at the lumbosacral level of the chick embryo: deletion of the dermamyotome. Dev Biol 122:540-558.
Tosney KW (1988) Proximal tissues and patterned neurite outgrowth at the lumbosacral level of the chick embryo: partial and complete deletion of the somite. Dev Biol 127:266-286.

Tosney KW, Landmesser LT (1984) Pattern and specificity of axonal outgrowth following varying degrees of chick limb bud ablation. $J$ Neurosci 4:2518-2527. 